\title{
Adherence to personal protective equipment use among healthcare workers caring for confirmed COVID-19 and alleged non-COVID-19 patients
}

\author{
Meike M. Neuwirth ${ }^{1,2^{*}}$ (D) Frauke Mattner ${ }^{1,2}$ and Robin Otchwemah ${ }^{1,2,3}$
}

\begin{abstract}
Adherence observations of health care workers (HCW) revealed deficiencies in the use of recommended personal protective equipment (PPE) among HCW caring in COVID-19 and non-COVID-19 wards during the first period of the SARS-CoV-2 pandemic in a university hospital in Germany. The adherence to wearing surgical face or FFP2-masks and disinfecting hands prior to donning and after doffing the PPE was significantly higher in COVID-19 wards However, there was no total adherence of $100 \%$ in COVID-19 wards.
\end{abstract}

Keywords: Coronavirus disease 2019 (COVID-19), Personal protective equipment (PPE), Adherence, Surgical face mask (SFM), FFP2-mask, Health care worker (HCW)

\section{Introduction}

The coronavirus disease 2019 (COVID-19) pandemic is a burden on societies and health care systems worldwide.

Regarding COVID-19 patient outcomes, medical risk factors and the capacity of health systems, especially the availability of well-trained health care workers (HCW), are decisive factors [1]. In Wuhan, staff shortage was found to be a major factor for the increased mortality rates [2], which was mainly due to COVID-19 infections among medical personnel acquired during patient care [2]. Particularly, if HCW were pre-symptomatic or asymptomatic carriers, they might have contributed to additional transmissions [3]. Therefore, protecting HCW from infection with SARS-CoV-2 is an important factor in controlling the SARS-CoV-2 epidemic [4].

\footnotetext{
${ }^{*}$ Correspondence: neuwirthm@kliniken-koeln.de

${ }^{1}$ Institute for Hygiene, Cologne Merheim Medical Centre, University

Hospital Witten/Herdecke Cologne, Ostmerheimer Str. 200,

51109 Cologne, Germany

Full list of author information is available at the end of the article
}

According to current knowledge, SARS-CoV-2 is thought to be transmitted via droplets or aerosols during close, unprotected contacts or by direct and indirect contact [4].

Since a vaccine or treatment is still lacking, current SARS-CoV-2 prevention measures aim to interrupt transmissions by maintaining adequate hand hygiene and the use of personal protective equipment (PPE) consisting of protective gowns, gloves, surgical face masks (SFM) or filtering face pieces (FFP2) and goggles or visors as indicated. However, PPE have not been always available, were not worn or worn incorrectly, and mistakes during donning and doffing were documented $[5,6]$. In a Study by Phan et al. [5] it was observed that $90 \%$ of doffing processes were incorrect. The most common errors occurred in the aspect of the correct removal of gowns (65\%) and contact with potentially contaminated surfaces (48\%) [5]. Ran et al. [6] reported that a lack of hand hygiene after contact with COVID-19 patients led to a higher risk of COVID-19 in Wuhan. For this reason, deficits in the use of PPE are to be identified and analyzed in order to provide $\mathrm{HCW}$ with targeted training on the correct and original author(s) and the source, provide a link to the Creative Commons licence, and indicate if changes were made. The images or other third party material in this article are included in the article's Creative Commons licence, unless indicated otherwise in a credit line to the material. If material is not included in the article's Creative Commons licence and your intended use is not permitted by statutory regulation or exceeds the permitted use, you will need to obtain permission directly from the copyright holder. To view a copy of this licence, visit http://creativecommons.org/licenses/by/4.0/. The Creative Commons Public Domain Dedication waiver (http://creativeco mmons.org/publicdomain/zero/1.0/) applies to the data made available in this article, unless otherwise stated in a credit line to the data. 
indication-appropriate use of PPE. In this context it is assumed that the general use of PPE has weaknesses and that HCW who are more experienced with respiratory and COVID-19 infections perform better than those who are inexperienced.

Here, we investigated the adherence to PPE use in COVID-19 and non-COVID-19 wards during the first epidemic phase of SARS-CoV-2 in a German university hospital.

\section{Methods}

A prospective observational study was conducted in eight wards (two intensive-, two intermediate-, and four standard care units) at a university hospital in Cologne/ Germany from February 27 to April 21, 2020. One intensive, one intermediate, and one standard care unit, all belonging to the Pulmonology Department and already experienced with infectious respiratory diseases before the COVID-19 pandemic, were exclusively dedicated to COVID-19 patients (hereinafter referred to as COVID19 wards). Staff on these wards treated patients with respiratory infections on a regular basis and therefore frequently use the required PPE items. The remaining wards on which no COVID-19 patients were treated were called non-COVID-19 wards.

Based on national recommendations, a checklist of 18 items was compiled [4] (Additional file 1). It contained items to assess the processes of donning, wearing, and doffing of the PPE with the necessary work steps such as the required hand disinfection (HD). In COVID-19 wards, FFP2-masks had to be worn (only in rooms with SARS-CoV-2 positive patients). Adherence to the single and total process steps of donning and doffing of all the observed situations was calculated as the number of "yes" answers divided by sum of the number of "yes" and "no" answers. If an activity was carried out incorrectly, it was considered as "no". Adherence is considered sufficient if the percentage value is greater or equal to $80 \%$. The observation results for the indication "no wearing of jewelry on hands and wrists" were inverted for the analysis due to their negative formulation.

Observations were performed by trained infection control nurses during patient care in the context of hand hygiene compliance observations, which are anchored in the legal requirements of the German Protection against Infection Act ( $\$ 23$ IfSG) and retrospectively evaluated. The correct wearing and fit of PPE were evaluated by the trained observer based on national recommendations [4]. The observed HCW were aware of and agreed with the observation situations. The observations were made openly. At the beginning of the COVID-19 pandemic, a hygiene plan was developed and all $\mathrm{HCW}$ were trained on the use of the necessary PPE before the observations. In addition, a general obligation to wear SFM was introduced throughout the hospital. PPE had to be worn when treating COVID-19 patients as well as when treating patients with other infectious diseases, such as multiresistant pathogens [7]. At no time during the observation period was there a lack of protective equipment at the observing COVID-19 and non-COVID19 wards.

Chi-square test was used as appropriate. The Chisquare test could only be calculated if the expected cell frequencies of one or more cells were greater than 5 . The Phi value was calculated as a measure of the effect strength.

\section{Results}

During the study period, 127 situations requiring PPE were observed in 87 nurses, 22 physicians, and 18 other employees (93 females; 34 males) (several multiple observations).

A total of 79 observations [intensive $(N=40)$, intermediate $(N=38)$, standard care units $(N=1)]$, which included 776 process steps, were performed on COVID-19 wards and 47 observations [intensive $(N=18)$, intermediate $(N=6)$, standard care units $(N=23)]$ with 410 process steps on non-COVID-19 wards.

The results of the observations showed a significantly higher overall adherence for COVID-19 wards experienced with respiratory tract infections compared to nonCOVID-19 wards, especially with regard to hand hygiene and donning of PPE (Table 1).

On the level of the individual process steps with regard to the indications of hand hygiene, COVID-19 wards showed significantly higher adherence rates for the indications "no wearing of jewelry on hands and wrists", "HD before donning PPE", and "final HD at the end of the doffing process" (Table 1 and Fig. 1).

For the donning of PPE, significantly higher adherence rates were also found in the COVID-19 wards for the indications "correct donning of SFM/FFP2", "correct removal of SFM/FFP2", "final HD", and "correct fit of SFM and FFP2 and additionally fit test of FFP2" (Fig. 1 and Table 1). Thereby, the indication "correct fit of SFM and FFP2 and additionally fit test of FFP2" showed the lowest adherence overall (Fig. 1 and Table 1).

For the doffing of PSA, no significant difference in total adherence between COVID-19 and non-COVID-19 wards could be observed. The COVID-19 wards showed a significantly higher adherence rate only for the single indication "correct doffing of SFM/ FFP2 masks".

The results of all observed indications are shown in Table 1. 
Table 1 Comparison of the adherence rates of the indications for the use of protective equipment by Healthcare workers in COVID-19 and non-COVID-19 wards

\begin{tabular}{|c|c|c|c|c|c|c|c|}
\hline & \multirow[t]{2}{*}{ Indications/process steps } & \multicolumn{2}{|c|}{$\begin{array}{l}\text { HCW in COVID- } \\
19 \text { wards }\end{array}$} & \multicolumn{2}{|c|}{$\begin{array}{l}\text { HCW in non- } \\
\text { COVID-19 wards }\end{array}$} & \multirow[t]{2}{*}{$p^{b}$} & \multirow[t]{2}{*}{$\varphi^{c}$} \\
\hline & & Adherence & $N$ & Adherence & $N$ & & \\
\hline \multirow[t]{6}{*}{ Hand hygiene } & No wearing of jewelry on hands and wrists & $99 \%$ & 79 & $69 \%$ & 48 & $<.001^{* * *}$ & .438 \\
\hline & HD before donning PPE & $85 \%$ & 59 & $54 \%$ & 41 & $.001 * * *$ & -.341 \\
\hline & HD at the end of the doffing of gowns and gloves & $80 \%$ & 59 & $81 \%$ & 32 & .856 & .019 \\
\hline & HD after doffing eye protection ${ }^{b}$ & $57 \%$ & 37 & $66 \%$ & 3 & & \\
\hline & final $\mathrm{HD}$ at the end of the doffing process & $91 \%$ & 65 & $54 \%$ & 35 & $<.001^{* * *}$ & -.420 \\
\hline & Total adherence to hand hygiene & $82 \%$ & 299 & $65 \%$ & 159 & $<.001^{* * *}$ & -.243 \\
\hline \multirow[t]{6}{*}{ Donning } & Correct donning of SFM and FFP2 & $89 \%$ & 47 & $70 \%$ & 47 & $.021^{*}$ & -.238 \\
\hline & Correct fit of SFM and FFP2 and additional fit test of FFP2 & $38 \%$ & 50 & $5 \%$ & 43 & $<.001^{* * *}$ & -.398 \\
\hline & Correct protective gown donning & $91 \%$ & 66 & $94 \%$ & 35 & .550 & .059 \\
\hline & Donning eye protection ${ }^{b}$ & $84 \%$ & 43 & $100 \%$ & 2 & & \\
\hline & Donning protective gloves & $93 \%$ & 72 & $97 \%$ & 33 & .422 & .078 \\
\hline & Total adherence to donning & $79 \%$ & 278 & $73 \%$ & 160 & $<.001^{* * *}$ & -.186 \\
\hline \multirow[t]{6}{*}{ Doffing } & Wipe disinfection of the work surface ${ }^{a}$ & $79 \%$ & 24 & $\begin{array}{l}\text { Desinfection } \\
\text { was not } \\
\text { required }\end{array}$ & 0 & & \\
\hline & $\begin{array}{l}\text { Doffing gowns and gloves without self-contamination } \\
\text { and without environmental contamination }\end{array}$ & $88 \%$ & 67 & $91 \%$ & 32 & .704 & .038 \\
\hline & Doffing eye protection ${ }^{b}$ & $94 \%$ & 36 & $100 \%$ & 2 & & \\
\hline & Correct doffing of SFM and FFP2 & $96 \%$ & 48 & $80 \%$ & 25 & $.029^{*}$ & -.255 \\
\hline & Disposal of the materials in correct waste ${ }^{a}$ & $100 \%$ & 48 & $100 \%$ & 32 & & \\
\hline & Total adherence to doffing ${ }^{e}$ & $95 \%$ & 199 & $93 \%$ & 91 & .389 & -.051 \\
\hline Total adherence to PPE use & & $85 \%$ & 776 & $76 \%$ & 410 & $<.001^{* * *}$ & -.109 \\
\hline
\end{tabular}

a Significance level could not be calculated

${ }^{b}$ Chi-square test could not be calculated because expected cell frequencies of one or more cells were less than 5

$c{ }^{*} p \leq .05$ (significant), ${ }^{* *} p \leq 01$ (highly significant), ${ }^{* * *} p \leq .001$ (highly significant)

${ }^{d} \varphi$ (Phi) $\leq .10$ (small effect), $\varphi=.30$ (moderate effect), $\varphi \geq .50$ (large effect)

e The indication "wipe disinfection of the work surface" was not considered in the calculation, as it was not required for non-COVID-19 wards

\section{Discussion}

Generally, the COVID-19 wards showed a higher total adherence with $85 \%$ of PPE use compared to the nonCOVID-19 wards with a total adherence of $76 \%$. Particularly, the increased adherence in the areas of hand hygiene and wearing PPE had a major impact on the overall adherence. For PSA doffing, there was no significant difference in adherence between COVID-19 (95\%) and non-COVID-19 wards (93\%) when removing the PPE.

The hand hygiene adherence of HCWs in the COVID19 wards was performed clearly above the national standard (median of $79 \%$ for all indications on intensive care units) [8] appropriate for a response to the pandemic challenge of SARS-CoV-2.

The adherence to the different recommendations "no wearing of jewelry on the hands and wrists", "HD before donning PPE", and "final HD after patient care" was significantly lower among HCW in non-COVID-19 compared to COVID-19 wards. The execution of HD in the process of doffing PPE, especially at the end of the process, is necessary in order not to contaminate oneself with pathogens [9]. In Wuhan, it was shown that a lack of hand hygiene increased the risk of transmitting SARS-CoV-2 from patients to $\mathrm{HCW}$ after hand contamination [6].

Although the COVID-19 wards performed better, we were surprised to detect deficits in fitting the masks (either SFM or FFP2) in a high proportion of all the observed wards. A leakage, especially by FFP2 masks and the incorrect wearing of SFM e.g. wearing the mask under the nose, could scotch any preventive effect. Probably the knowledge of the details on how to wear a mask correctly and the exercise on how to wear it in routine practice is still lacking. Our observation shows similar results to a quantitative fit test compliance study in which $38.2 \%$ of subjects failed the test [10]. 


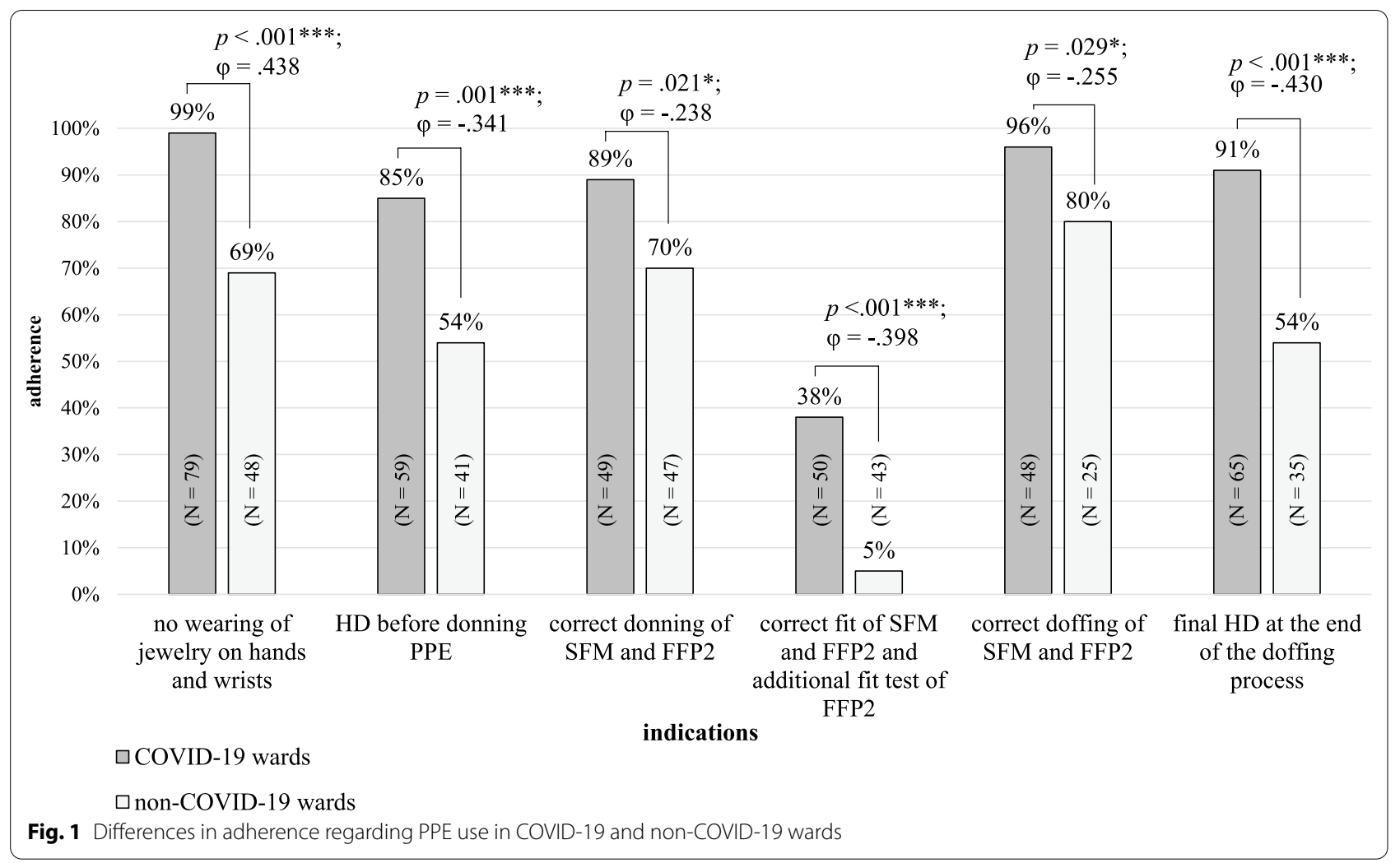

Deficits in the everyday handling of PPE have been observed before (especially in fitting, considering the correct sequence and correct use) and were found in $90 \%$ of the personnel [5]. The most common errors occurred in the correct removal of gowns (65\%) and contact with potentially contaminated surfaces (48\%) [5].

A reason for better hand hygiene adherence and performance in donning and doffing protective equipment could be due to the greater experience of the COVID-19 wards in dealing with respiratory tract diseases and PPE. In addition, increased situation-related higher awareness and risk awareness could also be a reason for better adherence in handling PPE.

In summary, we observed deficits in PPE use among all observed HCWs. Experienced HCWs showed higher adherence in the use of PPE than less experienced ones. However, despite the high awareness of the $\mathrm{HCW}$ regarding the dangers of SARS-CoV-2, it is surprising that they could not adhere to the fitting of FFP2masks in COVID-19 and SFM in non-COVID-19 wards in which undetected SARS-CoV-2-positive patients or $\mathrm{HCW}$ might have been present at time. Thus, there is still a clear need for training in the correct and indication-appropriate use of PPE in general and wearing masks in particular, to protect HCW from infection by droplet or even aerosol transmissible pathogens.

\section{Supplementary Information}

The online version contains supplementary material available at https://doi. org/10.1186/s13756-020-00864-w.

Additional file 1 Checklist for PPE observation of HCW in COVID-19 and non-COVID-19 wards.

\section{Acknowledgements}

We thank Regine Galante, Andreas Kirchler, Daniel Kreutzberger, Gudrun Gaksch, Ina Dombrowski, and Heyde Brauell for conducting the observation of the use of PPE. We also thank all the staff members who agreed to the observation.

\section{Authors' contributions}

MN is the corresponding author, elaborated this article, and developed tools for data collection. FM created and designed the study, critically revised this manuscript, and is the scientific supervisor. RO created and designed the study, critically revised this manuscript, and is the scientific supervisor and head of the study. All authors read and approved the final manuscript.

\section{Funding}

Open Access funding enabled and organized by Projekt DEAL.

Availability of data and materials Not applicable.

Ethics approval and consent to participate Not applicable. 


\section{Consent for publication}

Not applicable.

\section{Competing interests}

The authors declare that they have no competing interests.

\section{Author details}

${ }^{1}$ Institute for Hygiene, Cologne Merheim Medical Centre, University Hospital Witten/Herdecke Cologne, Ostmerheimer Str. 200, 51109 Cologne, Germany.

${ }^{2}$ Chair of Hygiene and Environmental Medicine, Faculty of Health/Department of Human Medicine, University Witten/Herdecke, Ostmerheimer Str. 200, 51109 Cologne, Germany. ${ }^{3}$ Department of Trauma and Orthopaedic Surgery, Cologne Merheim Medical Centre, University Hospital Witten/Herdecke Cologne, Ostmerheimer Str. 200, 51109 Cologne, Germany.

Received: 13 July 2020 Accepted: 24 November 2020 Published online: 10 December 2020

\section{References}

1. Zhou F, Yu T, Du R, Fan G, Liu Y, Liu Z, et al. Clinical course and risk factors for mortality of adult inpatients with COVID-19 in Wuhan, China: a retrospective cohort study. Lancet. 2020;395(10229):1054-62.

2. Pan A, Liu L, Wang C, Guo H, Hao X, Wang Q, et al. Association of public health interventions with the epidemiology of the COVID-19 outbreak in Wuhan. China JAMA. 2020;323(19):1915-23.

3. Arabi YM, Murthy S, Webb S. COVID-19: a novel coronavirus and a novel challenge for critical care. Intensive Care Med. 2020. https://doi. org/10.1007/s00134-020-05955-1.

4. Robert Koch Institut - Coronavirus SARS-CoV-2 - Empfehlungen des RKI zu Hygienemaßnahmen im Rahmen der Behandlung und Pflege von
Patienten mit einer Infektion durch SARS-CoV-2. https://www.rki.de/DE/ Content/InfAZ/N/Neuartiges_Coronavirus/Hygiene.html. Accessed 15 Apr 2020.

5. Phan LT, Maita D, Mortiz DC, Weber R, Fritzen-Pedicini C, Bleasdale SC, et al. Personal protective equipment doffing practices of healthcare workers. J Occup Environ Hyg. 2019;16(8):575-81.

6. Ran L, Chen X, Wang Y, Wu W, Zhang L, Tan X. Risk factors of healthcare workers with corona virus disease 2019: a retrospective cohort study in a designated hospital of Wuhan in China. Clin Infect Dis. 2020. https://doi. org/10.1093/cid/ciaa287/5808788.

7. Infektionsprävention im Rahmen der Pflege und Behandlung von Patienten mit übertragbaren Krankheiten: Empfehlung der Kommission für Krankenhaushygiene und Infektionsprävention (KRINKO) beim Robert Koch-Institut. Bundesgesundheitsblatt - Gesundheitsforschung - Gesundheitsschutz. Oktober 2015;58(10):1151-70.

8. Aktion Sauberer Hände. Compliance-Beobachtungen_Referenzdaten_2018.pdf. https://www.aktionsauberehaende.de/fileadmin/ash/ user_upload/pdf/messmethoden/Compliance-Beobachtungen_Refer enzdaten_2018.pdf. Accessed 08 June 2020.

9. CDC. Coronavirus Disease 2019 (COVID-19). Centers for Disease Control and Prevention. 2020. https://www.cdc.gov/coronavirus/2019-ncov/hcp/ using-ppe.html. Accessed 23 Oct 2020.

10. Degesys NF, Wang RC, Kwan E, Fahimi J, Noble JA, Raven MC. Correlation between N95 Extended use and reuse and fit failure in an emergency department. JAMA. 2020. https://jamanetwork.com/journals/jama/fulla rticle/2767023. Accessed 09 June 2020.

\section{Publisher's Note}

Springer Nature remains neutral with regard to jurisdictional claims in published maps and institutional affiliations.
Ready to submit your research? Choose BMC and benefit from:

- fast, convenient online submission

- thorough peer review by experienced researchers in your field

- rapid publication on acceptance

- support for research data, including large and complex data types

- gold Open Access which fosters wider collaboration and increased citations

- maximum visibility for your research: over $100 \mathrm{M}$ website views per year

At BMC, research is always in progress.

Learn more biomedcentral.com/submissions 